\title{
A note on design parameters for in-pit coal waste dumps in weak rock
}

PJN Pells Pells Consulting, Australia

\begin{abstract}
This paper summarises data from two very large slip failures of in-pit coal mine waste dumps in weak, slaking, claystones and siltstones in equatorial high rainfall areas. It explains why it is dangerously inappropriate to use undrained shear strength parameters for design and monitoring calculations, and recommends residual effective stress friction angles for remoulded, sheared basal layers. However, it is shown that understanding the geometric extents of such dump failures does require adopting undrained shear behaviour.
\end{abstract}

\section{Introduction}

This paper arises out of two very large failures of in-pit coal waste dumps on the island of Kalimantan, Indonesia. The first site, at Melawan, East Kalimantan is hard thermal coal in weak siltstones and claystones. The second site at Satui in West Kalimantan, is brown coal in even weaker siltstones and claystones.

The purpose of this paper is not to describe the failures in detail, nor to express views as to possible causes of the failures, it is to discuss important flaws in some current applications of soil mechanics in the design analyses of such dumps - flaws which have had their genesis in distortion of valuable guidelines widely used for waste dumps in the Queensland coal fields (Simmons \& McManus 2004).

A short description is given of each failure, and the associated geology, before proceeding to discuss the soil mechanics issues.

\section{Failure No. 1}

Figure 1 shows a plan of the first failure considered in this paper. It was very large, just over a kilometre wide and extending $1.5 \mathrm{~km}$ upslope along the mined-out pit floor. The volume of the slide was about 80 million cubic metres. Initial movement was noted about two weeks before the major failure occurred over a period of about two days. 


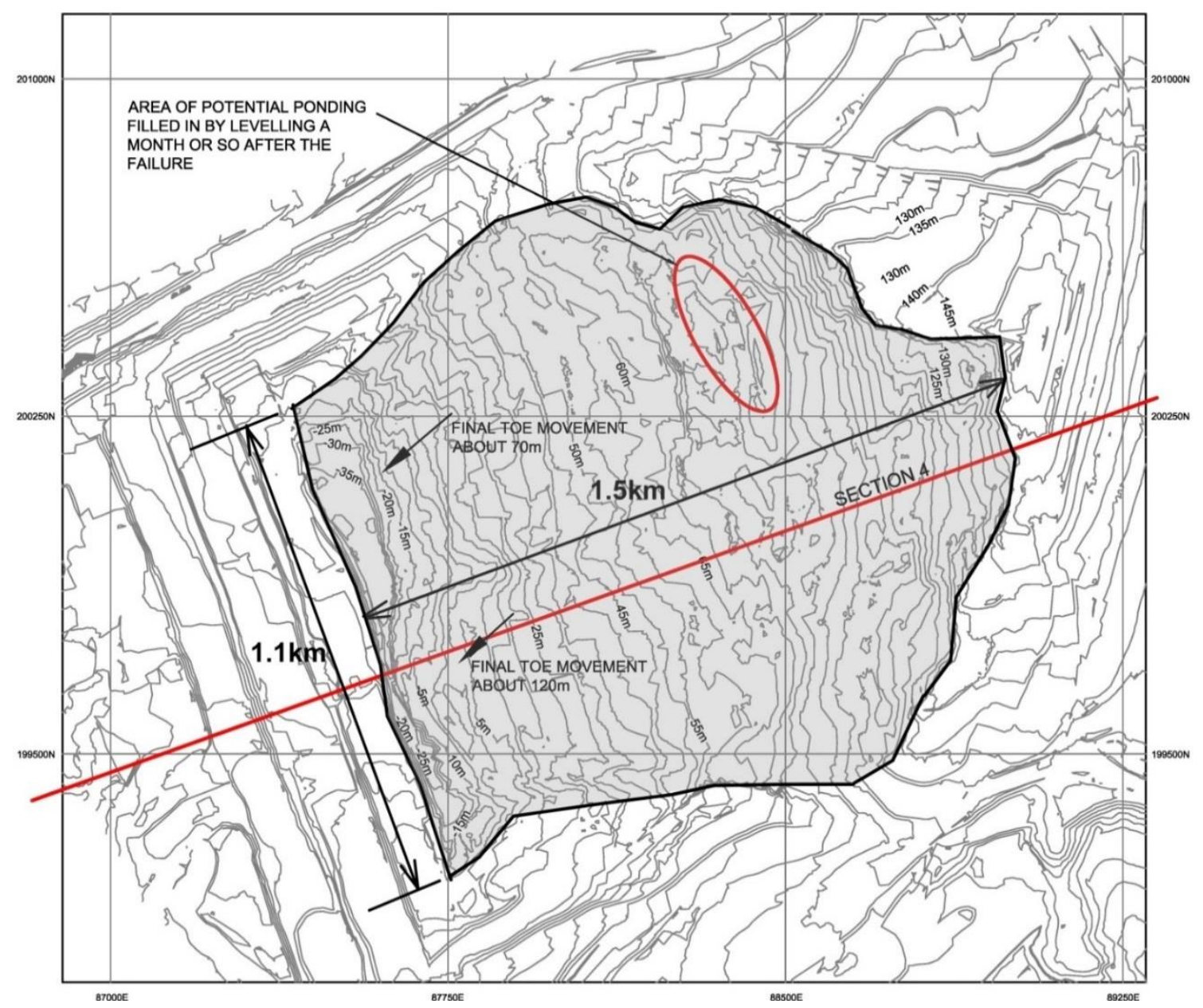

Figure 1 Plan of failure No. 1

The coal overburden comprises interlayered siltstones and claystones with some friable sandstone beds. The unconfined compressive strengths of the overburden rocks are typically about $4 \mathrm{MPa}$ to about $10 \mathrm{MPa}$. Many of the claystone beds, and some of the siltstones, show moderately high slaking when exposed in dump faces. The mine is in a high rainfall area of about $2,500 \mathrm{~mm}$ per annum.

There were only three piezometers in the dump. One, in the toe area was installed to beneath the floor about a year before the failure. This showed artesian flows out of a standpipe to about $2.5 \mathrm{~m}$ above floor level. The second was in about the centre of the dump and recorded water levels at about $75 \%$ of fill depth. The third was just upslope of the rear scarp of the failure and gave water levels at about $65 \%$ of fill depth.

Figure 2 shows the interpreted pore pressure profile along the section line given in Figure 1. It can be seen from Figure 1 that the base of the mined seam, being the floor of the dump formed a very gentle anticline, with the central part of the dump having a floor dip of about two degrees.

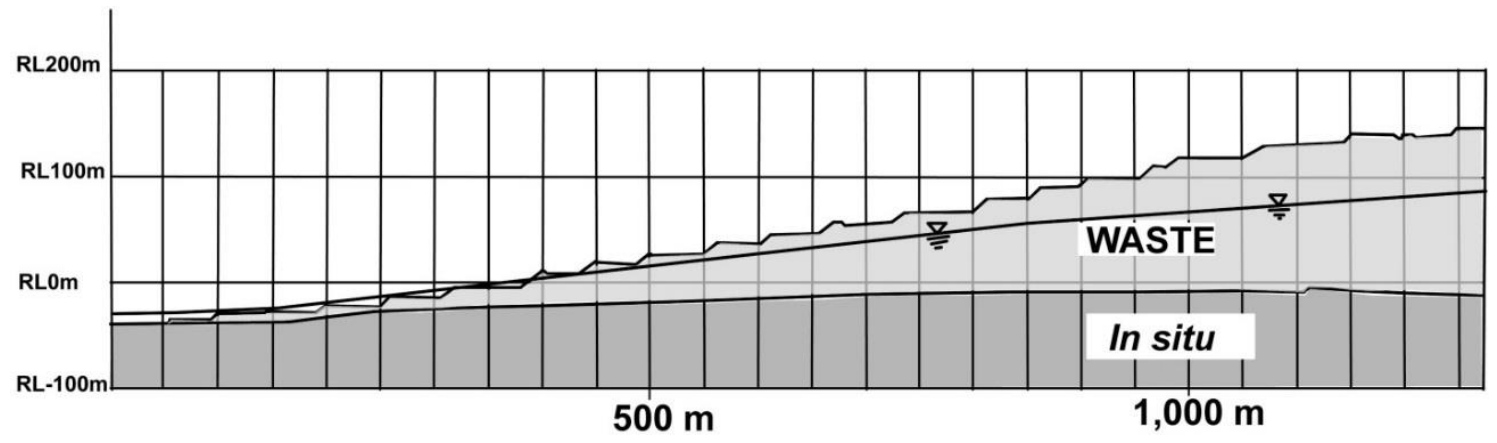

Figure 2 Cross-section prior to failure 
The design of the dump was based on a set of parameters, provided by a consultant, which were based on the concept set out by Simmons and McManus (2004). The essential feature of this concept is that the dump may comprise the following zones:

"Insitu coal-measure rocks may be either saturated or unsaturated prior to excavation, but the resulting spoil masses normally have no free water in the void spaces between particles.

Dumped material may compress to a limited degree due to particle crushing and rearrangement under the action of additional load. This is the normal "unsaturated" spoil condition, and corresponds to the strongest state that can be mobilised in the spoil mass. Due to the preferred orientations of particles and contacts, the unsaturated strength mode is believed to be anisotropic in character.

When significant quantities of water enter the void spaces within the spoil mass, the interparticle contacts and even the particles themselves are likely to slake, soften, and weaken. Test results show an accompanying significant reduction in mobilised shear strength, to what is termed the "saturated" strength mode, regardless of whether true saturation is achieved. Because there is still some preferred orientation of particles and contacts, the saturated strength is also anisotropic in character. Back-analyses have shown that the saturated strength mode is not reversible, even after free water is drained from the void space.

Saturation of a spoil mass with susceptible mineralogy can result in a third mode of strength development when sufficient shear distortion of the mass occurs by large deformation between softened particles. Back-analyses have shown this state to have, in practical terms, mobilised strength equivalent to the residual shear strength determined by direct shear tests on spoil fines. In the terminology of the framework, this is the "remolded" mode."

The writer agrees fully with this concept of Simmons and McManus.

For the dump described above only saturated and remoulded parameters were recommended. The writer again agrees with this - because of the very high rainfall and the in situ saturation of the overburden rocks.

The recommended shear strengths, given as effective stress parameters, are given in Table 1.

Table 1 Consultant shear strength recommendations

\begin{tabular}{ccc}
\hline Material & Unit weight & Strength parameters \\
\hline Saturated dump material & 1.9 & $\begin{array}{l}\sigma^{\prime} \leq 522 \mathrm{kPa}: \mathrm{c}^{\prime}=10 \mathrm{kPa}, \Phi^{\prime}=18.5^{\circ} \\
\sigma^{\prime}>522 \mathrm{kPa}: \mathrm{c}^{\prime}=32 \mathrm{kPa}, \Phi^{\prime}=16.3^{\circ}\end{array}$ \\
Remoulded dump material & 1.8 & $\begin{array}{l}\sigma^{\prime} \leq 600 \mathrm{kPa}: \mathrm{c}^{\prime}=10 \mathrm{kPa}, \Phi^{\prime}=17^{\circ} \\
\sigma^{\prime}>600 \mathrm{kPa}: \mathrm{c}^{\prime}=8 \mathrm{kPa}, \Phi^{\prime}=16.3^{\circ}\end{array}$ \\
\hline
\end{tabular}

However, the consultant also recommended that the basal layer of the dump be assigned the 'undrained' shear strength parameter of $\mathrm{c}_{\mathrm{u}}=45 \mathrm{kPa}$.

Despite there being little information of actual water levels in such dumps, the recommendation was made that designers assumed a piezometric surface at $50 \%$ of dump height at any point in the dump. Herein lies a major issue, because there is a recommended undrained shear strength, back-figured from failures linked to an assumed pore water pressure.

\section{$3 \quad$ Failure No. 2}

Failure No. 2 occurred $850 \mathrm{~km}$ away on the same island, but in a brown coal strip mine. It was about a year after Failure No. 1.

Figure 3 shows a plan of the slide, showing the sequence in which it developed. Figure 4 shows a side-on, $3 \mathrm{D}$ view. 


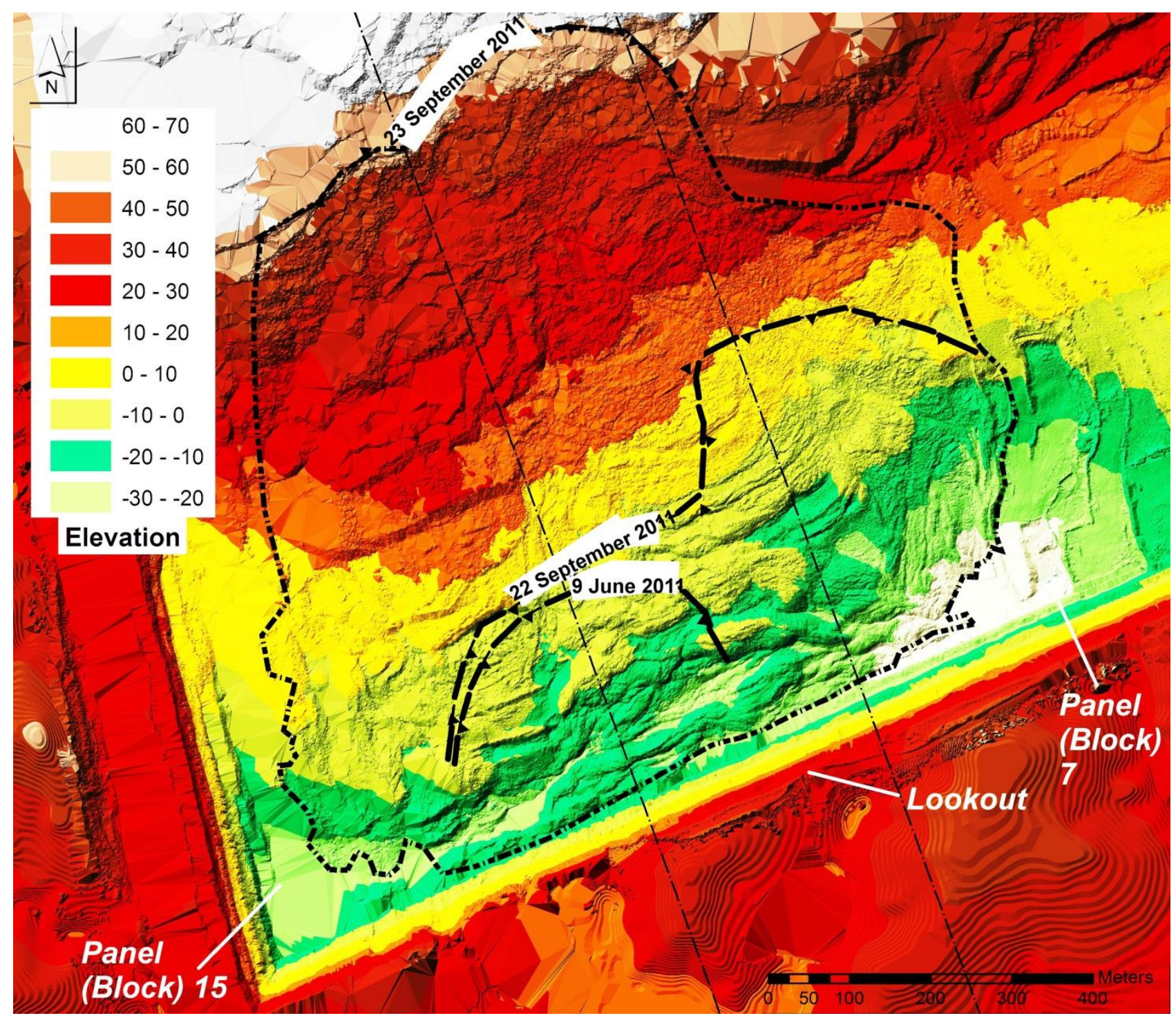

Figure 3 Plan of failure No. 2

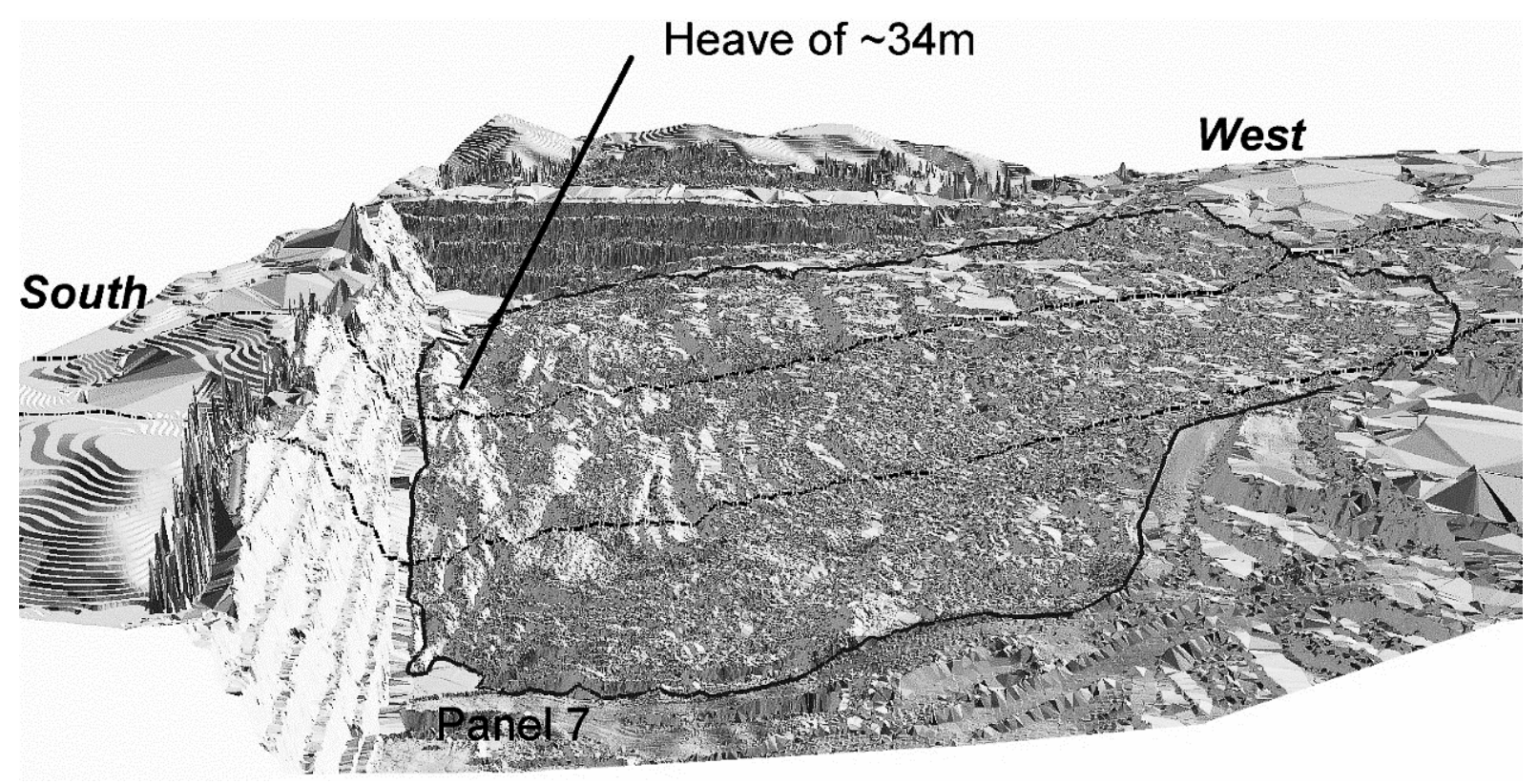

Figure 4 3D view of Failure No. 2 
A cross-section, approximately through the centre of the slide, is given in Figure 5 . In the area of the initial slip, the average floor dip is about five degrees; close to the highwall it reaches about six degrees. The volume of the final slip was about 10.5 million cubic metres. Piezometric pressures in the waste were available from two sets of piezometers.

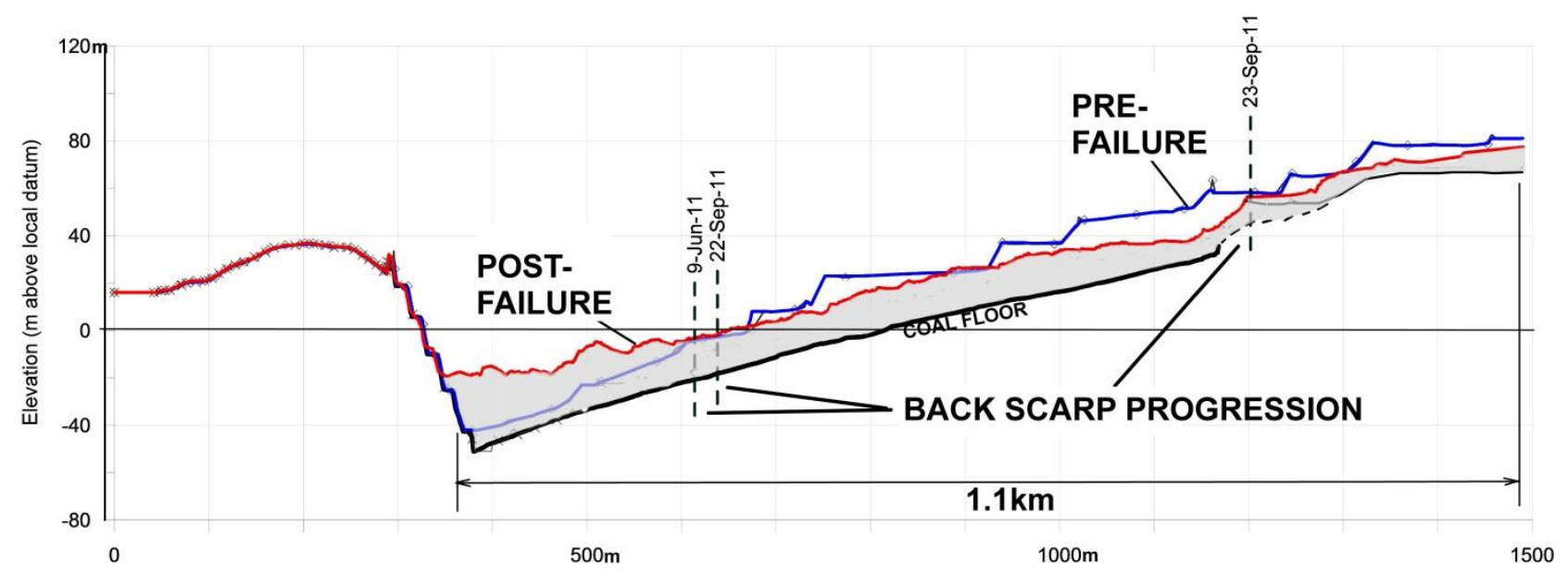

Figure 5 Cross-section through Failure No. 2

The pit is located in the southern part of a gentle anticline. Therefore, the pit floor dip increased gradually as the pit advanced to the south. The host rocks are very low strength claystones, siltstones and some friable sandstone. The unconfined compressive strengths of the host rocks vary from that of hard soil (less than $1 \mathrm{MPa}$ ) and very weak rock (UCS < $3 \mathrm{Mpa}$ ). Claystone is the predominant rock type.

Simple slaking tests were undertaken as described by Seedsman (1993), and in accordance with Seedsman's proposed classification system, the claystones and siltstones are 'clay shales', highly susceptible to breakdown in water and highly susceptible to remoulding under increasing normal and shear stresses (see Figure 6 for a test example).

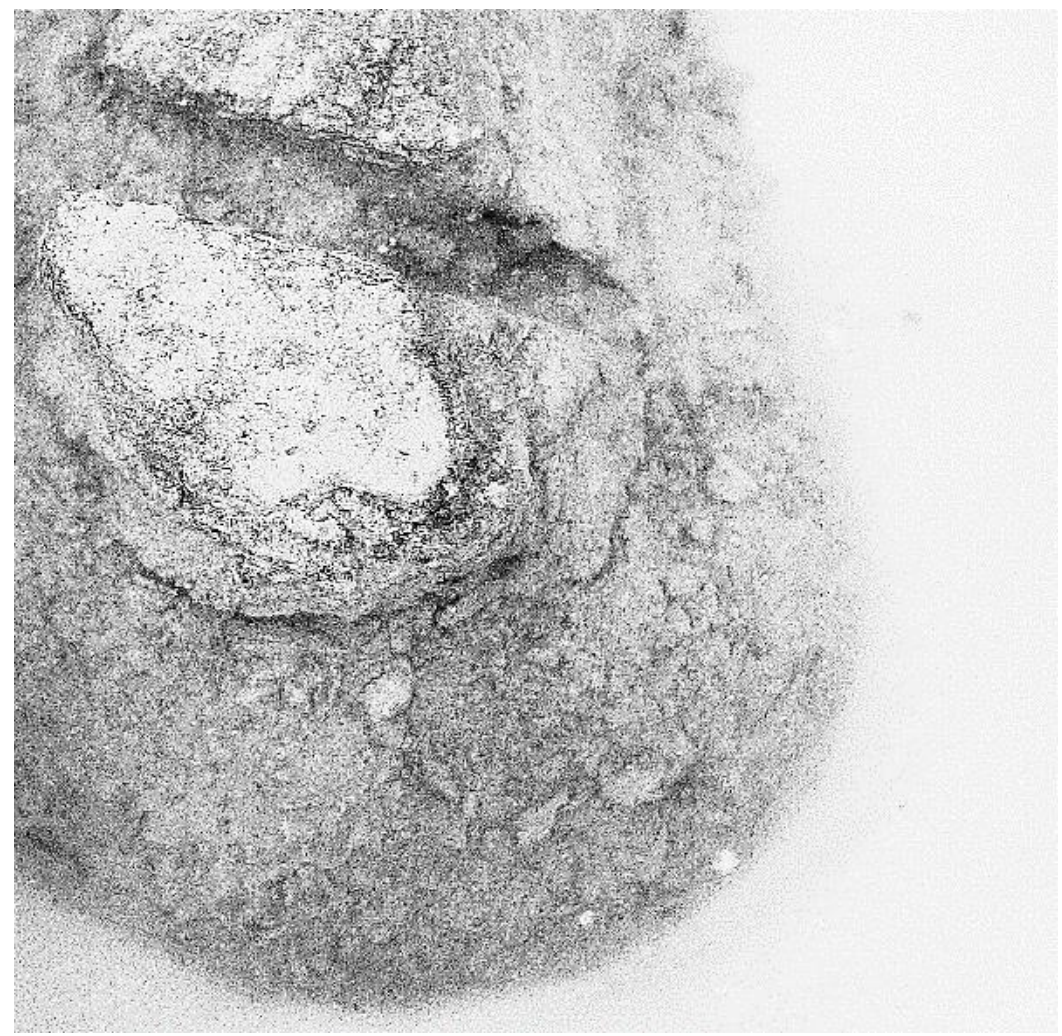

Figure 6 Claystone specimen in water after 15 minutes 


\section{$4 \quad$ The dilemmas of shear strength parameters}

\subsection{Simplified failure mechanism}

Whilst it may be appropriate to use computer-based, limit equilibrium, or finite element methods, to analyse the stability of dumps such as those described above, considerable insight is gained from a hand-calculation solution as illustrated in Figure 7, and given in Equation (1).

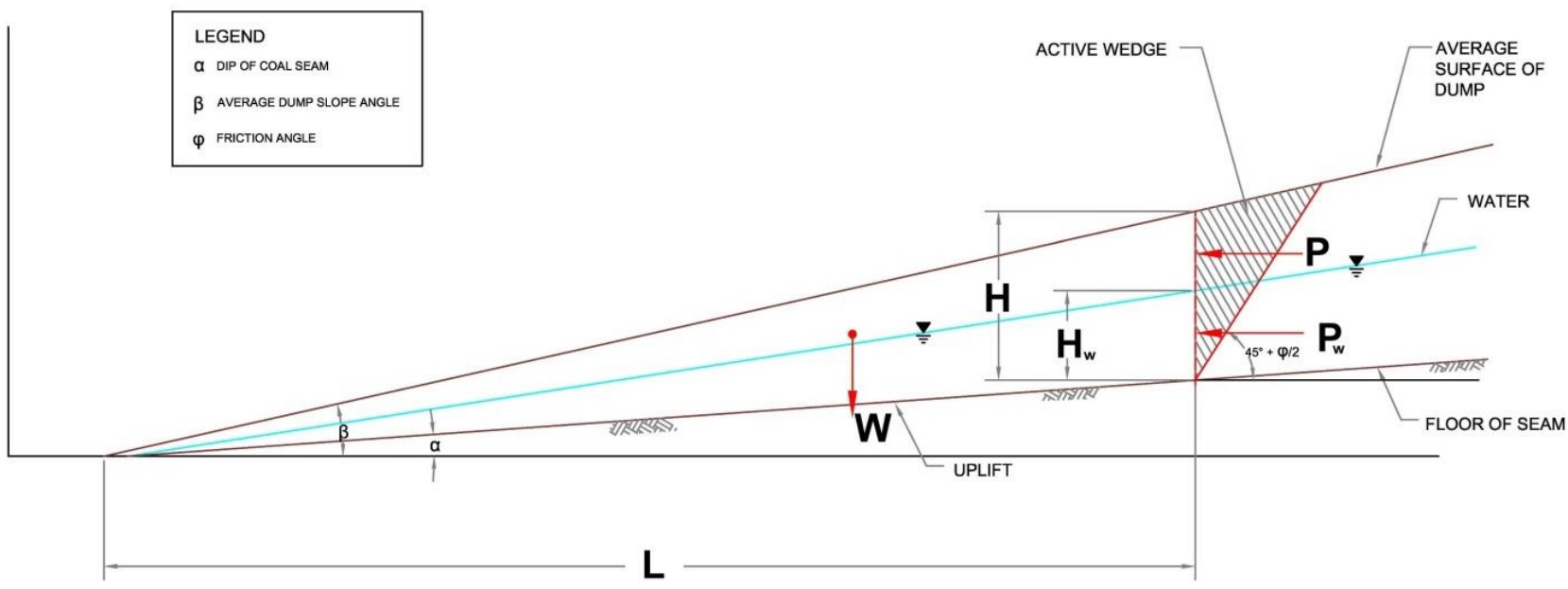

Figure 7 Model for hand calculation of Factor of Safety

From first principles, the following equation is determined for the Factor of Safety for the mechanism given in Figure 7:

$$
\mathrm{f}=\frac{C_{b} L+\frac{1}{2}\left(\gamma \cos \alpha-K_{w} \gamma_{w}\right)(\tan \beta-\tan \alpha) L^{2} \tan \emptyset_{\mathrm{b}}}{\frac{1}{2} L^{2}(\tan \beta-\tan \alpha)\left(\gamma \sin \alpha+K_{\mathrm{a}} \gamma\right)(\tan \beta-\tan \alpha)+K_{w} \gamma_{\mathrm{w}}(\tan \beta-\tan \alpha)}
$$

where:

$$
\begin{aligned}
& c_{b}=\text { cohesion on base of sliding mass }-\mathrm{kPa} . \\
& \emptyset_{\mathrm{b}}=\text { friction angle on base of sliding mass. } \\
& K_{w}=\text { ratio of height of water surface to height of dump }\left(H_{\mathrm{w}} / H\right) . \\
& K_{a}=\text { active earth pressure coefficient from active wedge. } \\
& L \quad=\text { length of base of slide (see Figure 7)-m. } \\
& \alpha, \beta=\text { base and slope angles (see Figure 7). } \\
& \gamma \quad=\text { bulk unit weight }-\mathrm{kN} / \mathrm{m}^{3} .
\end{aligned}
$$

In essence, the destabilising forces are:

- An effective stress force $P$ from the active wedge.

- A water force $P_{w}$ from the active wedge.

- A downslope force $(\mathrm{W} \sin \alpha)$ from the main sliding mass.

- An uplift force beneath the main sliding mass.

When Equation (1) is decomposed into the above components, it becomes clear that for waste dump failures of geometries similar to Failure Nos 1 and 2, the 'passive' block, with its basal sliding in the 'remoulded' zone, plays a dominant role. This is obvious when one considers the cross-section of Failure No. 2 at natural scale (see Figure 8 ). 


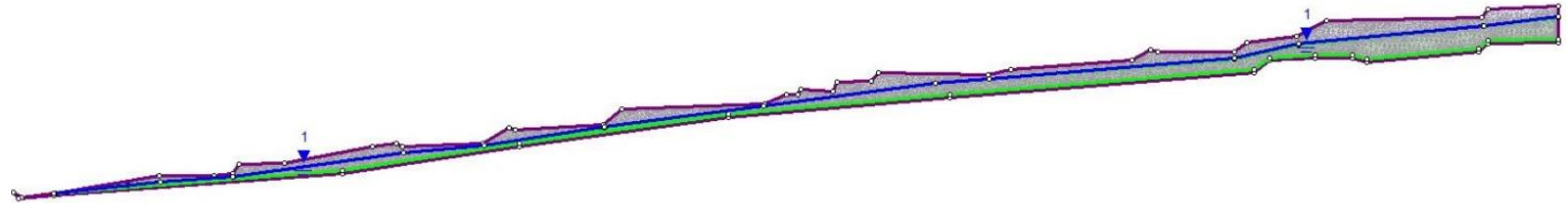

Figure 8 Finite element model of Failure No. 2

The real world is a little more complicated than shown in Figure 7 inasmuch as the floor of the dump is not a perfect plane, nor is the water surface. However, in regard to the key factors controlling stability, these departures are of secondary consequence. The key factors, which are not known accurately, are:

- The shear strength along the base of the slide.

- The water surface within the dump.

With poor knowledge of the key parameters controlling stability there is limited value in using sophisticated non-circular limit equilibrium stability analyses, or finite element analyses. Simple hand calculations using equations such as Equation (1) can allow rapid parametric analyses, thereby providing a sound basis for design decisions.

\subsection{Dilemma of Failure No. 1}

The writer performed hand calculations on site, subsequently checked by limit equilibrium and finite element analyses, of the failure using the parameters given in Table 1. It was found that with the lower recommended 'remoulded parameters of $c^{\prime}=8 \mathrm{kPa}$ and Phi-16.3 degrees, the Factor of Safety (FS) varied with piezometric level as follows:

- $\mathrm{FS}$ for water level $60 \%$ of dump height $=1.36$.

- $\mathrm{FS}$ for water level $80 \%$ of dump height $=1.18$.

- FS for water level $100 \%$ of dump height $=0.91$.

It very unlikely that the average water level in the dump exceeded $80 \%$ of dump height. This suggests that the zone of remoulded material at the base of the dump is of lower shear strength than given by the design-assumed remoulded parameters $\left(c^{\prime}=8 \mathrm{kPa} \Phi=16^{\circ}\right)$. It is probably that for a similar reason that, from other dump failures in the area, the consultant who provided the guideline parameters in Table 1 recommended a basal sliding layer with undrained shear strength of $45 \mathrm{kPa}$, coupled with piezometric level of $50 \%$ of dump height. The dilemma is the piezometric pressures then have no impact on the shear resistance of the passive block (see Figure 7), because of adoption of undrained shear strength.

Given the dominant role of the passive block, this becomes critical when calculations are repeated for actual piezometric pressures measured in the field. Without thinking about one's calculations one can become deluded into concluding that the measured pore pressures have insignificant impact on the probability of failure. The actual reason is that they have little impact because the dominant shear strength parameter is the $\phi_{u}=0$ assumption for the basal sliding surface. It is for this reason that Bishop and Bjerrum (1960) counselled, some 56 years ago, about the inherent dangers in using undrained shear strength parameters.

The writer concludes that, in the situation of Failure No. 1, it was appropriate to adopt effective shear strength parameters of between $\phi_{r}^{\prime}=10^{\circ}$ and $\phi_{r}^{\prime}=12^{\circ}$ for a basal sliding surface along the floor of the dump. These are considered to be reasonable residual shear strength parameters for sheared, high clay content, clay fill that has been remoulded and sheared at the interface by movements generated by incremental dump construction. 


\subsection{Dilemma of Failure No. 2}

Back-analyses of Failure No. 2 (see Figure 8) indicated that, for the adopted piezometric surface, the effective stress parameters would have to be as follows:

- Saturated waste.

$$
\begin{aligned}
& c^{\prime}=12 \mathrm{kPa} . \\
& \Phi^{\prime}=12^{\circ} .
\end{aligned}
$$

- Remoulded saturated waste.

$$
\begin{aligned}
& c^{\prime}=3 \mathrm{kPa} . \\
& \Phi^{\prime}=10.2^{\circ} .
\end{aligned}
$$

These are much lower than the parameters indicated from other failures in the area, and as adopted for the design.

Adoption of these low effective stress parameters provided reasonable modelling of the initial failure that occurred in the toe area of the slip (see Figure 3 ) but did not match the extensive full failure. This could only be understood if shearing of the basal layer involved undrained failure with $c_{u}=48 \mathrm{kPa}$.

So we have an opposite dilemma to Failure No. 1. There adoption of undrained shear strength of the basal layer masked the importance of high pore pressures in the dump. Here, with Failure No. 2, we cannot readily explain the geometry of the failure without adopting undrained shear behaviour in the basal layer.

\section{Conclusion}

The writer concludes that for large in-pit dumps in materials comparable to those described herein, design should be based on effective stress parameters using residual friction angle in a remoulded, sheared basal layer. However, when such dumps fail, the final geometry of the failure will be controlled by undrained shearing.

The writer remembers that this is a generality that Skempton taught the writer and his fellow students at Imperial College in 1969; so maybe there is little new under the sun.

\section{References}

Bishop, AW \& Bjerrum, L 1960, 'The Relevance of the Triaxial Test to the Solution of Stability Problems', in Research Conference on Shear Strength of Cohesive Soils, American Society of Civil Engineers, Boulder, Colorado.

Seedsman, RW 1993, 'Characteristics of Clay Shales' in J Hudson (ed.), Comprehensive Rock Mechanics, Pergamon Press, pp. $151-164$. Simmons, JV \& McManus, DA 2004, 'Shear strength framework for design of dumped spoil slopes for open pit coal mines', in Advances in Geotechnical Engineering: The Skempton Conference, Thomas Telford Limited, London, vol. 2, pp. 981-991. 